The Radio Journal - International Studies in Broadcast \& Audio Media

Volume 10 Number 2

(C) 2012 Intellect Ltd Article. English language. doi: 10.1386/rja0.10.2.145_1

\author{
ANNE O'BRIEN \\ National University of Ireland Maynooth \\ NIAMH GAYNOR \\ Dublin City University
}

\title{
Voice of the people? Objectives versus outcomes for community radio in Ireland
}

\begin{abstract}
Research has neglected to address the question of whether practitioners and the community groups served by community radio see it as a conduit of community empowerment and social change. This article explores this question through in-depth analysis of four community radio stations in Ireland. The central finding is that, while community stations subscribe to most of the ideals of community radio, practitioners do not generally see the stations as sites of social and political empowerment. Moreover, this outcome is not recognized as a benefit by the communities served by the stations. This is the case because of the policy framework, cultural traditions and training programmes central to community radio in Ireland, the weakness of linkages between stations and community groups and the failure of the latter to understand the unique remit of community radio.
\end{abstract}

\section{KEYWORDS}

community radio social change political benefit empowerment Ireland 


\section{INTRODUCTION: FRAMING OBJECTIVES AND OUTCOMES}

Community radio is an important and vibrant sector within broadcasting that is philosophically and structurally distinct from both commercial and public service models. It is audience owned and controlled, is autonomous from commercial interests and maintains a participatory relationship with its constituent communities. In its governance structures, its production practices and its on-air content, community radio is fundamentally different from all other forms of broadcasting. In their work, community radio practitioners set out to achieve objectives for the communities that they serve. According to the literature, the benefits that accrue to community radio include providing news and information relevant to the needs of the community (Janowski and Prehn 2003: 8), fostering and consolidating a sense of place (Keogh 2010), reflecting and constructing local culture (Meadows et al. 2005) and reducing the isolation of certain communities (Reed and Hanson 2006). Moreover, the production of programme content is expected to contribute to the social and political empowerment of community members by enabling dialogue between different sections of the community (Forde et al. 2002; Martin and Wilmore 2010; Siemering 2000). In short, community radio is intended to contribute to 'the democratization of communications and, consequently the fundamental change of existing power structures' (Elliott 2010: 7), promoting progressive social change (Baker 2007; Barlow 1988; Sussman and Estes 2005). Community radio differs fundamentally from its commercial and public service counterparts in that it opens up the airwaves to diverse voices, moving control and ownership of communication spaces away from commercial interests to local communities, and in the process democratizes community public spheres, facilitating social and political change.

However, research on community radio internationally has neglected to address the question of the extent to which the communities served by community radio stations experience the benefits that they supposedly derive from its provision (Meadows et al. 2005). This includes the issue of whether or not community groups see the radio stations as conduits of social change, emancipation and transformation. A central presumption of the theory relating to community radio is that it forms a distinctive media space. Within this intellectual framework, community radio is seen as functioning largely outside of the commercial and homogenizing tendencies of much of the mass media. Community radio is supposed to be insulated from hegemonic social forces and is expected to act as a platform of community participation, communication and emancipation (Elliott 2010; Meadows et al. 2005). This model of community media is one that is worth exploring through detailed research and one worth advocating because it is vital to protecting and defending diversity within the mass media. If media institutions in western society are to be diverse, with a variety of platforms provided for discussion, debate and deliberation, then a feasible and obvious way of underpinning this principle is to secure the broadest possible range of media outlets, with a broad scope of aims, objectives and participants. Community media has a vital role to play in securing this diversity within western mass media. Community radio responds to an agenda that is unique and fundamentally different to that of either public service broadcasting or commercial radio. By emphasizing participation and representation, community media sets an alternative bar for media output and engagement. This research responds to the objective of securing media diversity by exploring the extent to which 
community radio, in this case in Ireland, claims to uphold the theoretical objectives of progressive social and political change set out in international academic literature on the functions of community radio. This is an important question not only for academic researchers but also for broadcasters because, without its social agenda, community radio is reduced to a pale, lower-budget imitation of commercial local radio. Equally, the social change function of community radio is a vital focus for those engaged in community development because community radio is, ideally, meant to be an alternative platform for communication and engagement amongst communities. This article explores the question of the extent to which community radio in Ireland empowers local communities, through in-depth analysis of four community radio stations in the Republic of Ireland, and on the basis of this analysis explores the reasons why the Irish service may fail to live up to the theoretical presentation of the functions of community radio. Finally, it concludes that there is a need to question and further explore the feasibility or achievability of the theoretical objectives of community radio, which are presented as a blueprint for the sector.

\section{COMMUNITY RADIO AS A DISTINCTIVE MEDIA 'SPACE'}

In a mediascape dominated by commercial concerns, where even public broadcasting is shaped by commercial pressures, community radio represents a very distinct form of communication. Community radio began in the 1970s as a radical communication project aimed at re-appropriating the public sphere. It was instigated as an 'antidote' to the broader media institution, which was seen to have compromised its role as a 'watchdog' of society through processes of commercialization and privatization, which had in turn resulted in a re-feudalization of the public sphere (Habermas 1996) and the appropriation of public discourse to the manufacture of consent (Herman and Chomsky 1988). More recently, in the context of the growing significance of communication and information in post-industrial societies, Hackett and Carroll (2006: 2-10) highlight the mainstream media's ongoing democratic deficit as due to additional factors such as the 'centralisation of power, inequality, homogenisation, undermining of the sense of community, corporate enclosure of knowledge, elitist processes of communication, policy-making and the erosion of communication rights'. Similarly, trends towards dumbing down, Hollywoodization and trivialization of the important are all indicators of the media's continued failure to protect the public good (Splichal 2002). Splichal (2002: 11) notes, however, that despite fundamental questions about the function of the media in relation to the public, the idea of the media possessing some kind of 'watchdog' agenda persists in social commentary as a general function of the media in society. As a 'watchdog' on behalf of the public, the media acts to draw attention to political, economic or administrative abuses of power (Splichal 2002: 8-9). Commentators still accept that the media have social responsibilities, which include not only 'the nuts and bolts of reporting and representation' but also 'the principles which underlie these responsibilities', and which in turn need to be based on 'an interrogation of the increasingly global context in which they have to be exercised' (Silverstone 2007: 22). The goal of media democratization, in the sense of maximizing freedom and equality of communication, remains a challenge in an era of neo-liberal globalization, and it is to this latter agenda that the endeavour of community radio is addressed. 
Meadows et al. (2005) document the increasingly global reach that community radio has had in recent decades. The community radio sector worldwide is expanding and diversifying onto Internet platforms and yet it retains at its core a 'participatory' relationship with its varied communities (Girard 1992: 13). Community radio is 'ideally audience-controlled, autonomous and concerned with challenging power' (Elliott 2010: 9). The primary agenda of community broadcasting, which distinguishes it from public service and commercial equivalents, is that community radio constitutes a distinctive form of media with strong connections to the local community or community of interest that it is licensed to serve. The World Association of Community Radio Broadcasters (Association Mondiale des Radiodiffuseurs Communautaires, AMARC) reinforces this interpretation of community radio by proposing that AMARC's goal is to 'combat poverty, exclusion and voicelessness and to promote social justice and sustainable, democratic and participatory human development'; the organization works to 'reinforce the social, developmental and humanitarian impact of community media' (AMARC 2011). Barlow (1988: 101) similarly argues that community stations work to strengthen their communities

through the cultural production and reproduction of radio programming which is used as a tool for popular education, social justice and socioeconomic development ... to promote community dialogue and to present audio evidence in support of movements for progressive social change.

Servaes (1999: 260) adds that this implies for every community radio broadcaster

a democratic dimension; popular participation in the management of the station and in the production of its programmes. Community radio is accessible; it is neither the expression of political power nor the expression of capital. It is the expression of the population.

Thus a key objective of community radio is to work to empower communities, to promote dialogue and debate and to move towards social justice and progressive social change. Often, community radio very successfully achieves these ends, as documented by Chaparro Escudero (2004), Gordon (2010) and Elliott (2010), but community radio can also be less than representative of communities. For instance, as Günnel (2008: 87) observes

Many stations have difficulties involving the target groups they aim to address, for example, women and so-called 'socially disadvantaged groups' (people with a migrant background, with limited school education, elderly people, homeless etc.). Strategies to involve these target groups seem to be missing.

Moreover, Meadows et al. (2005: 181) point to the difficulty of identifying and interrogating community broadcast audiences and note that 'the one element absent from virtually all scholarly work on community broadcasting thus far is the audience'.

This article addresses this lacuna in knowledge by, first, outlining the extent to which the stations achieve these aims for their wider communities, 
and, second, by examining the extent to which Irish stations subscribe to the theoretical aims of community radio. In exploring these issues in detail, the research selected four community radio stations, two urban and two rural, from a total of twenty possible stations which had not previously been researched. Over a seven-month period in 2010, the authors conducted informal interview-based research in each of the four stations, observing how they were managed and operated. The authors interviewed 33 staff and volunteers from the stations, as well as conducted interviews with representatives from eight community groups, identified by station managers and volunteers as groups with which they worked, in each of the four catchment areas.

\section{THE SOCIAL AND POLITICAL BENEFITS OF COMMUNITY RADIO}

The key research findings revealed that, in defining the benefits generated by community radio, the consensus among the stations examined was that community radio in Ireland builds a sense of shared community, provides a localized and relevant information service for the community and provides training for volunteers. The Irish practitioners' views of the benefits to be derived from community radio very much tallied with the theoretical ideals delineated in the literature. However, the political dimension was lacking: stations did not emphasize their role as contributors to the progressive development of society, nor did they acknowledge that they should be channels of social and political change. Among the community groups within the stations' catchment areas, the service function of the stations overrode their process function. In other words, community actors engaged with the lower-level forms of participation offered by the stations, rather than the higher levels of direct control and access to the airwaves advocated in the theoretical aims of community radio. In short, the stations tended to work for rather than with communities, and the information and publicity service approach dominated any more radical or transformative political end. The benefits of community radio as understood by practitioners are outlined in detail below.

\section{BUILDING A COMMUNITY}

All participants in community radio stations noted that their broadcasts facilitated the engagement of local people with the broader community and in this way counteracted isolation and generated a sense of belonging amongst the wider community. Typically the stations researched were proactive in engaging at some level with community groups in their areas. They frequently made very intentional efforts to move outside the physical confines of their studios in order to interact with communities at particular events. Informants highlighted the emphasis the station placed on participating in events in the community. "The station comes to events and broadcasts ... we get out as often as possible, we work very hard on that' (personal communication). The stations were very open to promoting community events on air, and they were conscious of creating connections for networks of community groups to engage with each other as well as to connect to their client base through the medium of radio. They observed that this network was generated in part by other organizational connections held by the staff. 'With 100 plus volunteers each one of them is involved in at least one other organization so if something happens they're onto us' (personal communication). As a presenter on one 
station commented on the impact of community radio for community groups in their area:

The big benefit is that they have something they know they can access and they can build relationships and channel their information. A lot of community groups are connected to one another so we're becoming part of the network, if we can give them a hand we can benefit the community.

(personal communication)

Community development activists concurred that the stations contributed to the generation of a shared sense of community. One respondent highlighted the service provided by a station to people with disability in the town and its surrounds, offering them work experience and teaching them new skills. 'The station develops their own sense of independence ... it delivers real tangible outcomes' (personal communication). The other area she identified as an important achievement of the station was its work with smaller groups and communities from ethnic minorities, noting that the station 'gets people involved who otherwise wouldn't be involved ... they try to include the most isolated in the station' (personal communication). Another radio station had some links to a variety of formalized community groups in its area, in particular with a community centre in the local town which offered rehabilitative training, sheltered work, employment advice and a residential service to people with intellectual disabilities. The station was a favourite of residents and clients and was played all day in the centre. A number of residents visited the station, and staff and volunteers took the time to sit and chat with the visitors. As noted by many other people talking about the station, the centre's representative indicated that the local news (community diary), obituaries and religious services on Sunday were all extremely important to their residents and clients.

In this way volunteers and staff actively sought to include a wide range of local community groups in their programming and to connect community groups through the radio station. As a volunteer with one station succinctly put it, 'community radio is about a community speaking to itself and giving people that chance to participate, to be part of it and shape their own community' (personal communication). In yet another station, the manager emphasized that creating linkages was one of the station's main focuses. Both the manager and staff and volunteers interviewed within the station explicitly aspired to link with community groups and get the station more widely known in the area. But the issue of resources arose, with staff commenting on the difficulties faced in becoming more widely known. As one of the voluntary staff in the station noted, 'we'd like to do more of going out to particular areas ... I'd like to see more community centres getting involved but the problem is resources' (personal communication). One key commentator argued that the role of the community radio station was to facilitate the community in dialogue by bringing people into the station to participate in programmes and by ensuring that this constituted a positive experience for the participant. Essentially, community radio would not mediate people or explain people to the listeners; rather it would provide the technical facility for people to tell their own stories. As another key informant put it,

I think a social benefit that community media can do is bringing all these activists together, sharing their experiences and information and 
building on it. It's a synergy of information that's there. And this again is an entirely different form of media where it's really about information sharing. And I think ultimately that's the sort of social benefit that community radio can deliver for its community.

(personal communication)

This sense of constructing community and creating connections also existed in the sense of a community 'within' the stations. These internal communities of practitioners shared a common interest in community radio and through their interactions in the station they had created social networks that were inclusive of people who may otherwise have been quite marginalized in their social worlds. A presenter from one station noted the weight given by the station community to involving volunteers and ensuring that they felt comfortable in that environment. 'We have volunteers where this is like a home, it's a community, the people that come in, they feel like they belong here' (personal communication). As a community with a shared interest, which was inclusive of all volunteers, community radio provided a distinct benefit to those that participate by constituting a 'community within' the radio station while also generating a sense of connection to the wider community.

\section{LOCALIZED INFORMATION SERVICE}

A further benefit generated by community radio was the news and information service provided, which was localized for the community. Information services that radio practitioners named as important included highlighting citizens' information services or referring listeners to appropriate public service agencies. This service was deemed important to listeners because it was customized to their needs. At a more macro level, community radio also addressed broad educational and informational issues. For example, in its capacity to broadcast information to the local community, one station was particularly focused on its remit to educate and inform about disability. As the station manager put it,

We're the only community station that has a disability ethos written into its contract with the Broadcasting Authority of Ireland. We're very proud to be able to deliver an informative view about issues pertaining to disability, to allow volunteers with disability to come in work with us here, present shows, have community notice-boards and have programming dealing with topics pertaining to disability.

(personal communication)

In this way, community radio provided an informational service that was of benefit to communities because these issues went largely unaddressed by any other media service.

For the community groups interviewed, the primary importance of community radio to them was this publicity function. Stations generally publicized the activities of community groups, interviewed people involved in community centres and broadcast from the community groups' offices from time to time. The centrality of the impact of the publicity function for the community groups was undisputed. Through raising awareness of community groups, one radio station had led to an increase in the number of people availing themselves of a group's services. Similarly, in a second community centre 
which catered to 38 groups (over 130,000 people) in the area, the coordinator viewed the community radio service as particularly important in getting information to people. Echoing many other commentators, the community centre's coordinator observed that the larger commercial stations remained, by and large, disinterested in engaging with small community groups, but community radio had been very supportive of the centre's work with regard to publicity: 'they have room for us to get our message across ... they are a vital link for the community to sit down and listen to the community' (personal communication). Another large community development centre, which had over 50 paid staff, also made extensive use of the station to advertise its events and training. The centre staff member interviewed noted that, when an event was held, they always asked how people heard about it and found that 'approximately 60 percent of people hear about our events through the station' (personal communication).

\section{TRAINING BENEFIT}

Another benefit of community radio that practitioners acknowledged and valued was the training that it provided. Volunteers were trained in the practical and intellectual skills required to produce radio programmes, they gained invaluable on-air experience which allowed them to continually up-skill and they developed personal and professional skills from their exposure to the unique work environment of the community station. Typically, the training provision initially involved socialization into the workings of the station, beginning with an informal meeting with the station manager to discuss details of the areas that were of interest to volunteers and their availability to participate in activities. This progressed to volunteers doing voice tests for on-air work or alternatively finding roles that fulfilled the volunteers' specific individual needs and capabilities. The training was generally ongoing and multifaceted, with everything from researching, producing, editing and technical skills covered. The outcome of this training for participants varied from facilitating entry into professional broadcasting to more process-oriented benefits, such as facilitating people's discovery of new capacities and expansion of the range of their social abilities. Volunteers and participants gained insights or skills in the production and creative capacities required to make radio programmes, either by producing programmes or simply by participating in them on-air. For students and volunteers interested in pursuing careers in broadcasting, the training received at the station was invaluable in progressing this aim, by facilitating them in up-skilling technically, by increasing their confidence in their production abilities and by providing a supportive work environment in which to further their interest in community radio.

Thus the key benefits that community radio provided, according to both practitioners and community activists, were the provision of training, the provision of a localized news and information service and the generation of a sense of community belonging. However, although the central objectives of community radio according to the international literature includes the aim of acting as a channel for community emancipation, this was not strongly recognized or advocated in either the stations or the community groups researched. Community radio activists did not generally see their work as central to the task of social change and empowerment for community groups. Participants did, however, identify a role for community radio in promoting democratic communication, insofar as the stations all recognized the importance of promoting 
ideas and issues that were important to their communities. But this idea of the station 'giving voice' to those who might otherwise remain silent was limited to a sense of agendas being determined by listeners, rather than any more radical political interpretation of giving power to the marginalized or disenfranchised. While community radio definitely served as a support in publicizing community groups' work and services, it did not generally act as a portal for the voices of people attending the community groups, which rarely considered producing their own programmes or driving the agenda for public debate. The level of engagement between stations and wider community groups remained at the lower end of participation rather than at a higher end of empowering community groups to direct the activities and content of the station. The issue of political empowerment and engagement was simply not on the agenda for either radio or community group activists. When asked about the station's role in promoting debate on issues relating to marginalization and disadvantage in the area, one community group's representative noted that

We contacted them to put some events and issues on the radio which they did [examples cited include issues and events around International Women's Day, the National Day for the Eradication of Poverty and the 16 Days of Action against Violence Against Women], but on the whole, the station does not go for controversial issues ... It's a safe pair of hands, therefore people are not alienated, and that's alright.

(personal communication)

Reflecting further on their work with the station, community group representatives acknowledged that they should use the station more by working with people in local community groups to put together their own programmes. While staff within the centre felt that the station was open to this, they feel that the impetus, and a large amount of time and energy for this, would have to come from the centre itself and that 'this would be a huge thing' (personal communication). Staff noted that 'we could both [the station and centre] be more proactive in putting together a genuine community-based programme' (personal communication). While the station lacked this level of pro-activity in assisting groups produce their own programmes, centre staff note that it nonetheless was 'terribly supportive of community activity with a huge loyalty from the community ... we'd miss them terribly if they were gone and, without them, the place would be significantly poorer' (personal communication). But essentially the main purpose that community radio served for the groups in their areas was to act merely as a publicity channel for community groups and their activities rather than as forums for political discussion or as agents of political empowerment. The democratic nature of communication was clearly articulated as a positive and beneficial aspect of community radio but the objective of advocating for social and political change or acting as a channel for community education in the name of social justice and socio-economic development (Barlow 1988) were not articulated as central to the community radio agenda in Ireland.

While community radio activists subscribed very closely to most of the benefits of community radio as outlined by theoretical analysts, and saw it as a phenomenon that generated social gain, nonetheless a fundamental mismatch existed between the objective of promoting community empowerment as espoused in the international ideals of community broadcasting and the articulation of the objectives of the radio service expressed by radio practitioners and community groups in the transmission areas in Ireland. With 
regard to a key objective of community radio, to be the 'voice of the people' or to collapse the boundaries between the radio stations and the communities they serve, with the specific objective in mind of empowering local communities to generate social change, the research reveals that community radio stations fall short on both adopting and achieving this objective. Instead of acting to channel community groups onto the airwaves for developmental purposes, the stations acted instead in a more limited capacity, mostly to facilitate groups in publicizing issues, agencies and events. This raises the obvious question of why it is that Irish community radio does not adopt a political function. As this article will now argue, this is so because of the particular characteristics of Irish community broadcasting, including the policy framework that underpins it and the historical tradition of local, commercial and pirate radio provision in Ireland, and because radio training emphasizes radio production over community development. Moreover, community development groups have failed to integrate adequately with community stations and they have failed to understand the political agenda that is integrally connected to community radio; thus, they have used community radio only as a publicity forum, meaning that it does not achieve its political potential.

\section{EXPLAINING THE ABSENCE OF POLITICAL OBJECTIVES AND BENEFITS}

The absence of an explicitly political remit for community radio in Ireland may be explained by a combination of the historical evolution of community radio in Ireland, which has overlapped and intersected with the emergence of local commercial stations, the training amongst community stations, which disproportionately focuses on practical broadcasting issues rather than community activism, and the broadcasting policy, which does not explicitly adopt AMARC's political objectives. With regard to the latter, within the policy sphere, community radio guidelines in Ireland direct the sector towards generating social rather than political benefits. This in turn impacts on the stated objectives of the stations, as well as their operational ethos and the content of their programming schedules, all of which are determined by the broadcasting regulator's licensing processes. Community radio in Ireland has always had a very close relationship with the regulator. In fact, it emerged from a pilot project established in 1994 by the Broadcasting Commission of Ireland, the national broadcasting regulator. As part of the support structures put in place, the Commission part-adopted the 1994 AMARC Community Radio Charter for Europe (AMARC 2012) as a statement of the objectives community stations should aim to achieve. An initial policy document defined community radio as characterized by a not-for-profit ownership where membership, management, operation and programming were primarily undertaken by members of the community at large (BCI 2001: 3). Stations included in the community broadcasting strand were expected to 'promote and support active participation by this community at all levels in the operation; (and) operate in a manner which is in keeping with the ethos or value system which underpins community activity' (BCI 2001: 3). Most recently, community radio in Ireland was bound by the 2009 Broadcasting Act, which altered the definition of community radio to include a provision on social benefit: 'programme material in pursuance of the contract will be effected with the sole objective of - (i) specifically addressing the interests of, and seeking to provide a social benefit to, the community concerned' (Stationery Office 2009). Ultimately, the objective of community 
radio practitioners in Ireland was to meet the ideal of generating social benefit for communities, but the more strongly stated political directive contained in the AMARC charter, whereby community radio 'responds to the needs of the community which it serves and contributes to its development in a progressive manner, promoting social change', was absent from the Irish policy framework and in part explains the lack of political emphasis on social change evident in the operation of community radio in Ireland.

The absence of an explicitly politically oriented curriculum was also evident in the training of community radio participants undertaken by the stations and the umbrella body CRAOL, which tended to emphasize the development of broadcasting-related skills rather than the education of practitioners as community activists. This in effect meant that there was not a very explicit level of awareness of community radio's political agenda amongst the practitioners researched and, consequently, less evidence of demand for changes to the status quo or overall orientation of community radio in Ireland. As noted earlier, the training that community radio participants engaged with in the stations researched tended to focus on the production and creative skills required for programme-making. None of the stations researched had run training sessions specifically on community development or on the politics of the international community radio movement. This was perhaps the case because the community radio umbrella organization CRAOL facilitated training for members at an annual weekend training 'Féile' or festival. However, the training offered by the forum, for volunteers in 2010 for instance, focused disproportionately on broadcasting or radio skills rather than community development issues. From a total of sixteen training workshops, four had what could be considered a broadly community development, as opposed to radio skills, focus. Specifically, these workshops addressed topics such as media literacy, intercultural issues, creating a women's network and steps to social inclusion. Thus, within the community radio movement, the agenda of political change is not very heavily articulated within the training programmes provided for participants.

Moreover, historically the boundaries between commercial and community radio in Ireland have been very fluid and blurred. Community radio in Ireland was unavoidably influenced by the domination of pirate commercial stations that developed in tandem with it. In the 1970s and 1980s, between 70 and 80 commercial, music-driven, pirate stations (BCI 2006) were on air in Ireland. The distinction between these often small-scale local commercial stations and community radio was not always apparent, even to broadcasters in the stations, with both entities frequently using the word 'community' in their names. Undoubtedly many pirate community stations were very clear on the remit and purpose of community radio and these joined together to form the National Association of Community Broadcasters (NACB) in 1983, which subscribed to the ideals of AMARC, supported aspirant community radio groups and lobbied for the inclusion of community radio in legislation to regulate the sector (Day 2009: 33). But when the Radio and Television Act of 1988 established the independent radio sector in Ireland, some of the early community stations received local radio licences and became commercial stations, which further blurred distinctions between the two entities. This was, in fact, the history of one of the stations researched for this article, which evolved from a pirate community to a licensed commercial station in 1990 and reverted back to a community station when it lost its commercial licence in 2004. The boundary between commercial and community stations remained 
porous into the 1990s. When an invitation to apply for community radio licences was finally issued by the regulator in 1994, this initiative attracted not only AMARC-style community radio practitioners but also pirate radio era broadcasters, who were interested in gaining a commercial licence under 'community' pretences. This lack of distinction between community and commercial enterprises was not helped by the fact that the first eleven licences issued for community radio in Ireland were 'adaptations of commercial stations' licenses and were not always suitable for the community model' (Day 2009: 38). Thus the boundaries between commercial and community radio were historically blurred in Ireland because of the dominance of the commercial, local pirate radio model, the tendency of these stations to name themselves as community stations, the awarding of commercial licences to formerly community stations and vice versa and the failure of the regulator to acknowledge early on the unique nature and remit of community radio.

On the community development side, community groups in the stations catchment areas did not express an understanding of community radio as a social or political resource, saw them only as publicity conduits and failed to understanding the political objectives of community radio. The publicity or training service provision element of community radio was at the forefront of community groups' understandings of the role that it played, and there was very little sense that community radio was about a broader agenda of community empowerment and social change. A representative from one community group in the catchment area of one of the stations noted that the agency had found the station useful in promoting its work and getting messages out in relation to the various events it was organizing. 'We would ring the station to promote events, we'd have our staff speaking on radio around topics and that's very useful in getting messages out' (personal communication). The community group did a lot of work with ethnic minority groups, and both the Equality Officer and the Ethnic Minority Officer were regularly interviewed on air. The station had also broadcast their events using its mobile outside broadcast unit and, at the request of the group, organized a one-day workshop on radio for members of a local youth group. 'It was a new opportunity for people who haven't done radio before to engage ... and the station even gave them a chance to go on air ... and some of them did' (personal communication). This community group clearly viewed its local community station more as a portal for information or training for the community, rather than as a means of providing a voice to people directly.

Moreover, for the most part, community activists perceived the community radio stations as indistinct from local commercial operations. One organization representative did not distinguish between commercial newspapers and community radio and noted that local newspapers still remained the agency's first port of call with regard to publicity for its activities. 'We would still tend to use the local papers more than community radio. I think that's just 'cause we're more used to them ... it's easier to email a piece or a report to them ...' (personal communication). In one case, the representative of the local community group interviewed was only vaguely aware of the work of the community radio station. Clearly staff and volunteers in the stations need to be more proactive in building links and communicating in direct and effective ways the aims and ethos of their station if they wish to engage with communities beyond the station. This pro-activity includes setting out what makes a community radio station distinct from its commercial counterparts, in particular emphasizing that the station offers far more to community groups and members than just 
publicity, the principal function of the station highlighted by the representatives interviewed. The fact that community groups did not express an understanding of community radio as a social or political resource signals the fact that there is a basic mismatch between the political objective of democratic participation and empowerment claimed by the international community radio movement and the actual manner in which community radio operates in Ireland. There is a disconnect between radio practitioners' understandings of the objectives that community radio achieves and the actual impacts of community broadcasting as articulated by the community groups that the stations purport to represent, which is limited nearly exclusively to a publicity service model. The failure of community radio stations to advocate for social and political change, as well as the failure of community groups to understand and engage with the transformative capacities of community radio reduce the emancipatory community radio project in Ireland to a publicity 'service' for community groups, with particular consequences for both community empowerment and the public sphere, within which community radio risks becoming 'less distinguishable from mainstream media' (Robinson 1997: 17).

\section{CONCLUSION}

While community radio internationally claims a very definite objective of working to strengthen communities, to promote popular education and community dialogue and to empower community groups to move towards social justice and progressive social change agendas, this research shows that in Ireland this objective is not overtly articulated by community radio practitioners, despite the fact that the umbrella organization CRAOL (2012) commits to 'promote democracy, human rights and sustainability, to engage with social exclusion, and to act as a catalyst for integration and inclusion'. The stations are linked to local community groups only through their publicity 'service' role, rather than through potential roles as catalysts for community empowerment and social change. While philosophically and structurally, community radio in Ireland is 'volunteer-directed, and takes on a wide variety of social aims according to the collective goals of participants' (Elliott 2010: 8), the understanding of the social benefits that accrue to community radio, as expressed by its practitioners in Ireland, are limited to a service model, and the international movement's aim of community emancipation are not either objectives of the community stations in Ireland or benefits that are recognized by the community groups that the stations claim to serve. While community radio stations in Ireland claim to subscribe to the objectives of the international community radio movement, they fail to embody the ideal of acting to facilitate community empowerment, which means that this is not an acknowledged outcome for communities on the ground. This perhaps reduces community radio in Ireland to something of a performance, where the stations are claiming to constitute part of an international movement to generate social and political progress, but where in practice the Irish stations exclude this overriding objective of community radio, to empower communities.

Alternatively, perhaps this case raises a question about whether community radio has 'failed' if it fails to meet the objectives or ideals set out in the international literature, or whether the literature is less than fully relevant to the practice of community radio. This research shows that community radio in Ireland does not fully match the ideals set out in theory, but the key significance of this finding is that the Irish case raises a challenge to 
researchers of community radio to more fully explore aspects of community radio practice vis-à-vis its theoretical models. This question can be explored in more detail and more fully addressed if similar research is conducted, both in more detail and across other cases in other states. On that basis, a clearer picture can emerge as to why community radio might 'fail' to prioritize a sociopolitical agenda. Such research would do much to promote the engagement of community radio with this vitally important aspect of its remit, but it will also force the further refinement of theoretical models of community radio practice, so that the former comes to more realistically explain the latter, the actual practice of community radio on the ground. With regard to the Irish case, if community radio is to be both a 'genuine community experience and a genuine radio experience' (Barlow and Johnson 2008: 78), it needs to move beyond the publicity or service model and begin to engage more with constituent community groups, in order to generate stronger linkages between the station and the public, to transform the understanding of community radio that exists among constituent groups and to shift from the provision of a mere service to achieve higher levels of community engagement. Only by doing this can these radio stations truly become the voice of the people.

\section{ACKNOWLEDGEMENTS}

The Broadcasting Authority of Ireland funded the research from which this article draws. The authors would like to thank the two anonymous reviewers for their thorough and insightful comments.

\section{REFERENCES}

AMARC. (2011), 'Strategic Plan 2011-2014', http://europe.amarc.org/index. php?p=Strategic_Plan-2011-2014\&amp;l=EN. Accessed 20 March 2012.

_ (2012), 'Community radio charter for Europe', http://europe.amarc.org/index. php?p=Community_Radio_Charter_for_Europe. Accessed 21 March 2012.

Baker, S. (2007), 'Young people and community radio in the northern region of Adelaide, South Australia', Popular Music and Society, 30: 5, pp. 575-90.

Barlow, D. and Johnson, S. (2008), 'Finding a voice community radio: Role sustainability and practice', The Radio Journal - International Studies in Broadcast and Audio Media, 6: 2\&3, pp. 75-85.

Barlow, W. (1988), 'Community radio in the U.S.: The struggle for a democratic medium', Media, Culture and Society, 10: 1, pp. 81-105.

Broadcasting Authority of Ireland. (2009), Broadcasting Bill, Dublin: Stationary Office.

Broadcasting Commission of Ireland. (2001), BCI Policy on Community Radio Broadcasting, Dublin: BCI.

_ (2006), FAQs about us, history of the BCI, http://www.bci.ie/faqs/faq about_history.html. Accessed 19 May 2010.

Chaparro Escudero, M. (2004), 'Third sector radio in Spain', The Radio JournalInternational Studies in Broadcast and Audio Media, 1: 3, pp. 177-92.

CRAOL. (2012) 'What does community radio offer?', http://www.craol.ie/2/0/ about.html. Accessed 5 May 2010.

Day, R. (2009), Community Radio in Ireland: Participation and Multiflows of Communication, Cresskill, NJ: Hampton Press.

Elliott, P. (2010), 'Another radio is possible: Thai community radio from the grass roots to the global', The Radio Journal - International Studies in Broadcast and Audio Media, 8: 1, pp. 7-22. 
Forde, S., Foxwell, K. and Meadows, M. (2002), 'Creating a community public sphere: Community radio as cultural resource', Media International Australia, 103: 1, pp. 56-67.

Girard, B. (1992), A Passion for Radio: Radio Waves and Community, Montreal: Black Rose Books.

Gordon, J. (2010), Notions of Community: A Collection of Community Media Debates and Dilemmas, Oxford: Peter Lang.

Günnel, T. (2008), "The "dual role" approach: Encouraging access to community radio', The Radio Journal - International Studies in Broadcast and Audio Media, 6: 2\&3, pp. 87-94.

Habermas, J. (1996), 'Civil society and the political public sphere', in J. Habermas (ed.), Between Facts and Norms: Contributions to a Discourse Theory of Law and Democracy (trans. W. Rehg), Cambridge, MA: The MIT Press.

Hackett, R. and Carroll, W. (2006), Remaking Media: The Struggle to Democratic Public Communication, New York: Routledge.

Herman, E. and Chomsky, N. (1988), Manufacturing Consent: The Political Economy of the Mass Media, New York: Pantheon.

Janowski, N. W. and Prehn, O. (2003), Community Media in the Information Age: Perspectives and Prospects, Cresskill, NJ: Hampton Press.

Keogh, S. B. (2010), 'The importance of place in community radio broadcasting: A case study of WDVX, Knoxville, Tennessee', Journal of Cultural Geography, 27: 1, pp. 77-98.

Martin, K. and Wilmore, M. (2010), 'Local voices on community radio: A study of "our Lumbini" in Nepal', Development in Practice, 20: 7, pp. 866-78.

Meadows, M., Forde, S., Ewart, J. et al. (2005), 'Creating an Australian community public sphere: The role of community radio', The Radio Journal International Studies in Broadcast and Audio Media, 3: 3, pp. 171-87.

Reed, M. and Hanson, R. E. (2006), 'Back to the future: Allegheny Mountain Radio and localism in West Virginia community radio, Journal of Radio Studies, 13: 2, pp. 214-31.

Robinson, E. (1997), 'Flagship faces rough waters: US community radio in crisis', Interadio, 8: 1, p. 17.

Servaes, J. (1999), Communication for Development: One World, Multiple Cultures, Cresskill, NJ: Hampton Press.

Siemering, W. (2000), 'Radio, democracy and development: Evolving models of community radio', Journal of Radio Studies, 7: 2, pp. 373-78.

Silverstone, R. (2007), Media and Morality: On the Rise of the Mediapolis, Cambridge, UK: Polity Press.

Splichal, S. (2002), 'The principle of publicity, public use of reason and social control', Media, Culture and Society, 24: 1, pp. 5-26.

Stationery Office. (2009), Pt.6 S.72 [No. 18.] [2009.] Broadcasting Act 2009, Dublin: Stationery Office.

Sussman, G. and Estes, J. R. (2005), 'KBOO Community Radio: Organizing Portland's disorderly possibilities', Journal of Radio Studies, 12: 2, pp. 223-39.

\section{SUGGESTED CITATION}

O'Brien, A. and Gaynor, N. (2012), 'Voice of the people? Objectives versus outcomes for community radio in Ireland', The Radio Journal - International Studies in Broadcast \& Audio Media 10: 2, pp. 145-160, doi: 10.1386/ rajo.10.2.145_1 


\section{CONTRIBUTOR DETAILS}

Dr Anne O'Brien is Academic Director with Kairos Communications/Centre for Media Studies, National University of Ireland Maynooth. Her main research interests are the politics of development and the role of media in social change. Her book The Politics of Tourism Development examines the role played by state and private sector politics in development in Ireland.

Contact: Kairos Communications/Centre for Media Studies, National University of Ireland Maynooth, Co. Kildare, Ireland.

E-mail: anneobrien@kairoscomms.ie

Dr Niamh Gaynor is a Lecturer in the School of Law and Government, Dublin City University. Her main research interests are the politics of development and social change, community media and the relations between community and the state. Her book Transforming Participation? The Politics of Development in Malawi and Ireland highlights the role of media in opening political space for social change.

Contact: School of Law and Government, Dublin City University, Glasnevin, Dublin 9, Ireland.

E-mail: niamh.gaynor@dcu.ie

Anne O'Brien and Niamh Gaynor have asserted their right under the Copyright, Designs and Patents Act, 1988, to be identified as the authors of this work in the format that was submitted to Intellect Ltd. 
Copyright of Radio Journal: International Studies in Broadcast \& Audio Media is the property of Intellect Ltd. and its content may not be copied or emailed to multiple sites or posted to a listserv without the copyright holder's express written permission. However, users may print, download, or email articles for individual use. 